\title{
Educação terapêutica para diabéticos: os cuidados com os pés na realidade de pacientes efamiliares
}

\author{
Therapeutic education for diabetics: \\ foot care in the reality of patients and family members
}

Ligia de Loiola Cisneros ${ }^{1}$

Luiz Alberto O liveira Gonçalves²

${ }^{1}$ Departamento de Fisioterapia, Universidade Federal de M inas Gerais. Av. Antonio Carlos 6.627, Pampulha. 31270-901 Belo Horizonte M G. ligialoiola@ufmg.br ${ }^{2}$ Departamento deCiências Aplicadasà Educação, UniversidadeFederal de M inas Gerais.
Abstract Knowing the reality of foot care practice taught in educational programs for diabetics can enhance the therapeutic education success. This study presentstheperception sof diabeticsand their family members about primary cares to prevent complications on foot. A qualitative exploratory study was conducted in an intentional sample of 30 diabetic with neuropathic risk of foot injuries as well as 11 of their family members, participants of a preventive program offered in a public health center in the city of Porto Alegre, Rio Grande do Sul State, Brazil. A semi-structured interview with open-ended questions about experiences of foot care was conducted. Thematerial transcribed was submitted to qualitative content analyses. Patients need assistance to foot care practice. A cooperative and interactivenetwork isformed behind patients, perceived as a support or a threat to freedom. The importance of preventive measures becomes evident from their personal experiences of a complication or those of others'. Therapeutic education to prevent diabetic foot complications must consider therelations of assistance formed around the patient. It is necessary to break the silence of the evolution of the disease in order to motivate the patient to the adoption of preventive measures. Key words Health education, Diabetic foot, Qualitative research
Resumo Conhecer a realidadeda prática dos cuidados com os pés ensinados nos programas educativos para diabéticos pode contribuir para um melhor resultado da educação terapêutica. Esteestudo apresenta significados atribuídos por pacientes diabéticos e seus familiares aos cuidados primários que visam prevenir complicações nos pés. Foi realizada uma pesquisa qualitativa exploratória sobre amostra intencional de trinta diabéticos, neuropatas, com risco de lesão nos pés e familiares de onze deles, que participaram de um programa deprevenção em uma unidade desaúde pública do município de Porto Alegre(RS). Foi aplicada uma entrevista semidirigida com questões abertas sobrea experiência doscuidados com os pés. 0 material transcrito foi submetido à análise qualitativa de conteúdo. Os pacientes precisam de ajuda para realizar os cuidados com os pés. U ma rede de solidariedadeeinteraçõeséformada por trás dos pacientes, percebida como um apoio ou uma ameaça à liberdade. É a experiência própria ou alheia de uma complicação que evidencia a importância da prevenção. A educação terapêutica para prevenção de complicações nos pés de diabéti cos deve levar em conta as relações de assistência formadas em torno do doente. É preciso romper o silêncio da evolução da doença para motivar o pacienteà adoção das medidas preventivas. Palavras-chave Educação em saúde, Pé diabético, Pesquisa qualitativa 


\section{Introdução}

A Organização Mundial da Saúde define como educação terapêuticaa capacitação de pacientese familiares nas habilidades para o manejo do tratamento ou para adaptações particulares e para a prevenção de complicações das doenças' ${ }^{1}$. Essas intervenções educativas direcionam-se a formar um indivíduo consciente deseu problema desaúde eresponsável por seu cuidado diário. Sua importância éreconhecida no tratamento de doenças crônicas, como o diabetes mellitus, em queo doente vai evolta a um serviço de saúde com sua doença ecom a responsabilidade pela gestão diária dela, que inclui cuidados continuados para a preven ção de complicações².

$N$ a prevenção das ulcerações nos pés queprecedem aproximadamente $85 \%$ das amputações em membros inferiores de pessoas diabéticas ${ }^{3}$, a educação terapêutica é parte essencial dos programas que abordam cuidados primários4. $\mathrm{Hi}$ gienedos pés, tratamento de calos, infecções fúngicas e lesões cutâneas são elementos essenciais desses programas educativos ${ }^{5}$. No entanto, estee outros esforços terapêuticos para minimizar os problemas nos pés provocados por diabetes não nos permitiram, ainda, alcançar a meta da Declaração de São Vicente de reduzir em $50 \%$ as amputações $^{6}$. Os resultados de ensaios clínicos que avaliaram a eficácia preventiva da educação do diabético para prevenção das lesões nos pés não são conclusivos ${ }^{7}$. Os insucessos parecem estar relacionados à não adesão dos pacientes ao que Ihes é recomendado ${ }^{8}$. A investigação por métodos qualitativos, que vem crescendo na diabetologia, apresenta a realidade dos cuidados diários com a doença a partir da experiência de quem a vivencia. A questão do cuidado dos pés, sob a perspectiva do doente (um conhecimento aprofundado do significado da doença, do cuidar-se, das necessidades, das angústias e ansiedades do doente) pode apontar novas direções para a educação terapêutica, de forma a melhorar seus resultados.

Este estudo teve como objetivo conhecer e apresentar significados atribuídos por pacientes diabéticos e seus familiares aos cuidados primários que visam prevenir complicações nos pés, com o intuito de contribuir para um melhor resultado da educação terapêutica.

\section{M étodos}

A abordagem qualitativa preocupa-se em dar sentido ou interpretar fenômenos em termos designificações trazidas para eles pelas pessoas em estudo ${ }^{9}$. N esta perspectiva, foi utilizada neste trabalho a pesquisa clínico-qualitativa, que éuma proposta metodológica aplicadaao setting dos cuidados com a saúde ${ }^{10}$. Foi realizada uma pesquisa exploratória com trinta pacientes diabéticos com risco de lesão nos pés e familiares de onze deles. Como instrumento de coleta de dados, foi utilizada a entrevista semi-dirigida (semi-estruturada) com questões abertas sobre o tema central (cuidados dos pés) e suas questões específicas.

0 estudo foi realizado em uma unidade do Sistema Ú nico de Saúde da cidade de Porto Alegre (RS) que oferecia, na ocasião, consultas de acompanhamento e orientações para prevenção do pé diabético. Foi realizado um rastreamento para identificar diabéticosque apresentavam risco de lesão nos pés por neuropatia. Para identificação do grau de risco, foi feita a estesiometria, utilizando-se o monofilamento de SemmesWeinstein de 10 gramas $^{11}$. Sujeitos com a condição de interesse (risco de lesão nos pés) e que estavam sendo acompanhados pela entrevistadora há pelo menos um ano foram informados sobre as propostas do estudo e convidados a participar e a trazer um familiar para a entrevista. Aqueles que concordaram assinaram o termo de consentimento livre e esclarecido. A amostra foi fechada por saturação (número suficiente para permitir reincidência de informações que não acrescentassem dados substancialmente novos àqueles já obtidos) e variedade de tipos no caso do familiar entrevistado (parentesco ou relação social), como sugerido por Turato ${ }^{12}$.

Os procedimentos descritos a seguir foram seguidos na operacionalização das entrevistas de forma a assegurar as condições ótimas para realizar a pesquisa e para assegurar sua validade ${ }^{10}$. As entrevistas foram previamente marcadas com o paciente, atendendo à sua disponibilidade. $0 \mathrm{~s}$ encontros foram realizados em recinto reservado e familiar para os sujeitos, a saber, consultórios do serviço onde era regularmente atendido pela entrevistadora, garantido, assim, a atmosfera para uma reação transferencial positiva entrevistadorentrevistado. A entrevista foi iniciada com uma questão gerativa narrativa de forma a encorajar o sujeito a contar a história do diagnóstico de sua doença e do seu envolvimento no seu tratamento ${ }^{13}$. As questões específicas, dentro do foco da pesquisa pretendida, foram feitas seguindo a li- 
nha de pensamento e de experiências relatadas pelo entrevistado, pela livre associação de idéias. Esta flexibilidade permitiu que transcursos diferentes de entrevista eo surgimento denovos tópicos fossem acolhidos, assegurando possibilidades indefinidas de aprofundamento do tema. 0 familiar que acompanhou o paciente na entrevista foi estimulado a relatar sobre a recepção do diagnóstico do diabetes mellitus no ambiente familiar e sobre o envolvimento dos membros da família nos cuidados que a doença requer, especificamente aqueles relacionados aos pés.

Paciente efamiliar compareceram juntos, sendo as perguntas dirigidas, inicialmente, ao paciente na presença do familiar. Em seguida, o paciente se retirava da sala de consulta e o familiar permanecia para responder às suas questões específicas. As entrevistas tiveram uma duração média de vinte minutos e foram gravadas em fita cassete com a autorização do pacientee de seu familiar. As entrevistas foram transcritas e o material escrito (sem as anotações da entrevistadora) foi entregue ao entrevistado para que esse verificasse a fidelidade da transcrição de seu depoimento.

Para a análise de conteúdo, as categorias foram formuladas pela entrevistadora e por outro analista dos dados. A pós leituras repetidas e flutuantes para familiarização com o material transcrito, os temas de conteúdo comum foram identificados, por sua regularidade evariedade ${ }^{14}$. Foram consideradas as informações reincidentes bem como as ímpares com potencial explicativo ${ }^{15}$. Seguindo o método descrito por Bardin ${ }^{16}$, foram estabelecidas as categorias de acordo com a frequência da presença de itens de sentido, o que permitiu uma análise quantitativa dos discursos. As categorias foram discutidas entre os analistas (triangulação) para se ter clareza do que estavam representando e para estabelecer categorias consensuais. Foram feitas relações entre as categorias, buscando suas interligações e também contrastes.

A aprovação ética para realização deste estudo foi obtida da Secretaria M unicipal de Saúde dePorto Alegre(RS) e as condutas para execução seguiram as normas para pesquisa envolvendo seres humanos definidas na Resolução n 196/96 do Conselho $\mathrm{N}$ acional de Saúde.

\section{Resultados ediscussão}

A Tabela 1 apresenta a caracterização da amostra. Há uma predominância de sujeitos do sexo masculino. A idade dos sujeitos variou de 44 a 83 anos, sendo que $53,3 \%$ da amostra de pacientes estavam acima de sessenta anos. As profissões em sua maioria estavam ligadas ao setor de serviços e ao comércio. A escolaridade mostrou-se bastante heterogênea. 0 tempo de diagnóstico da doença, ao ingressar no estudo, variou de 0,5 a 37 anos, sendo que apenas quatro pacientes tinham menos de dez anos de diagnóstico. Portanto, para a maioria, a convivência com a doença e com o tratamento já fazia parte de seu cotidiano. $\mathrm{N}$ a mesma tabela, podemos localizar informações acerca do grupo familiar de cada indivíduo: média de 3,6 indivíduos por família, com renda girando em torno de 4,6 salários mínimos (variando de um a 12,5 salários).

$\mathrm{Na}$ Tabela 2, estão os dados referentes à distribuição da amostra por risco de lesão nos pés. $N$ as categorias 1 e 2 (perda da sensibilidade protetora nos pés e insensibilidade associada à deformidade ou hiperpressão plantar, respectivamente) estavam $60 \%$ dos sujeitos. Foram classificados na categoria de risco 3 (com história de úlcera neuropática) $13 \%$ dos sujeitos e $27 \%$ em risco 4 (deformidadeehiperpressão plantar neuropática e história de úlcera neuropática).

A partir da análise do corpus das entrevistas, foram definidos três temas principais: gestão da doença, cuidados com os pés e prevenção das complicações neuropáticas nos pés. As categorias que compõem cada um desses temas, com suas respectivas frequências, estão apresentadas, em ordem decrescente, no Quadro 1. A seguir, estão apresentados os temas analisados, pela ordem de importância da contagem frequencial, com alguns trechos das narrativas que ilustram as categorias.

A complexidade da gestão da doença requer 0 envolvimento dos familiares

A inspeção, higiene e limpeza dos pés como ações preventivas são parte de uma rotina do paciente diabético, que envolve também cuidados com alimentação, prática de atividadefísica, administração de medicamentos e consultas e exames regulares ${ }^{17}$. $\mathrm{N}$ as entrevistas, a gestão da doença foi relatada de forma evidente (64 ocorrências), possivelmenteporqueos problemas nos pés, como complicações crônicas, estão diretamente relacionados ao controle da doença. As narrativas de $28(68,3 \%)$ dos entrevistados evidenciaram que uma nova realidade foi criada na vida dos sujeitos para se adaptarem ao tratamento disciplinado e rigoroso do diabetes: A minha neta me ajuda muito. Só me dá doce se 0 
Tabela 1. Caracterização da amostra estudada: variáveis sociodemográficas e clínicas.

\begin{tabular}{ccc}
\hline Sujeito Características & $\begin{array}{c}\text { Cuidador } \\
\text { entrevistado familiar } \\
\text { (salário mínimo/ } \\
n^{\circ} \text { de pessoas no } \\
\text { domicílio) }\end{array}$ \\
\end{tabular}

1 Homem, 57 a, divorciado, eletricista, não alfabetizado, diabético há 12 anos

2 Mulher, 70 a, casada, costureira aposentada, $1^{\circ}$ grau, diabética há 15 anos

3 Mulher, 57 a, casada, doméstica, $1^{\circ}$ grau, diabética há 11 anos

4 Homem, 53 a, casado, contador, $3^{\circ}$ grau incompleto, diabético há 10 anos

5 Homem, 76 a, casado, costureiro aposentado, $1^{\circ}$ grau, diabético há 10 anos

6 Homem, 63 a, casado, motorista, $1^{\circ}$ grau incompleto, diabético há 17 anos

7 Mulher, 71 a, casada, costureira aposentada, $1^{\circ}$ grau, diabética há 20 anos

8 Mulher, 56 a, casada, do lar, $1^{\circ}$ grau, diabética há 16 anos

9 Homem, 66 a, casado, padeiro aposentado, $1^{\circ}$ grau incompleto, diabético há 12 anos

10 Mulher, 75 a, viúva, comerciaria aposentada, $1^{\circ}$ grau incompleto, diabética há 20 anos

11 Mulher, 58 a, divorciada, telefonista, $1^{\circ}$ grau, diabética há 28 anos

12 Mulher, 53 a, casada, do lar, 1o grau incompleto, diabética há 14 anos

13 Mulher, 70 a, viúva, secretária aposentada, 10 grau incompleto, diabética há 20 anos

14 Homem, 71 a, casado, administrador aposentado, $3^{\circ}$ grau, diabético há 37 anos

15 Homem, 82 a, viúvo, marinheiro aposentado, $1^{\circ}$ grau, diabético há 16 anos H omem, 60 a, casado, motorista aposentado, $1^{\circ} \mathrm{grau}$ incompleto, diabético há 21 anos

17 Homem, 44 a, casado, motorista, $1^{\circ}$ grau, diabético há 10 anos

18 Homem, 70 a, casado, sapateiro aposentado, $2^{\circ} \mathrm{grau}$, diabético há 4 anos Homem, 66 a, viúvo, técnico administrativo aposentado, $2^{\circ} \mathrm{grau,}$ diabético há 12 anos

20 Mulher, 50 a, solteira, técnica de enfermagem, $2^{\circ} \mathrm{grau}$, diabética há 17 anos

21 Mulher, 59 a, viúva, passadeira, 10 grau incompleto, diabética há 0,5 ano

22 Homem, 67 a, casado, auxiliar administrativo aposentado, $1^{\mathrm{a}}$ grau, diabético há 15 anos

23 Homem, 76 a, casado, pedreiro aposentado, 1ํgrau incompleto, diabético há 10 anos

$24 \mathrm{H}$ omem, 63 a, viúvo, mecânico aposentado, $1^{\circ}$ grau incompleto, diabético há 15 anos

25 Homem, 83 a, viúvo, auxiliar administrativo aposentado, $2^{\circ} \mathrm{grau}$, diabético há 6 anos

26 Homem, 57 a, divorciado, supervisor técnico, 1o grau incompleto, diabético há 16 anos

27 Mulher, 45 a, casada, costureira, $1^{\circ}$ grau incompleto, diabética há 10 anos

28 Homem, 54 a, viúvo, representante comercial, $2^{\circ} \mathrm{grau}$, diabético há 18 anos

29 Mulher, 58 a, casada, doceira, 1ํgrau incompleto, diabética há 21 anos

30 Homem, 63 a, casado, tipógrafo, 1o grau incompleto, diabético há 3 anos

\begin{tabular}{|c|c|}
\hline Esposa & $4,2 / 5$ \\
\hline Esposo & $3 / 3$ \\
\hline - & $4,2 / 4$ \\
\hline Esposa & $9,2 / 6$ \\
\hline - & $7 / 2$ \\
\hline - & $2 / 2$ \\
\hline - & $1,7 / 6$ \\
\hline - & $2,9 / 4$ \\
\hline Esposa & $7,9 / 5$ \\
\hline Neta & $2,5 / 6$ \\
\hline Irmã & $6,7 / 4$ \\
\hline - & $3,1 / 3$ \\
\hline - & $2 / 2$ \\
\hline- & $4,2 / 2$ \\
\hline- & $6 / 1$ \\
\hline- & $4,6 / 4$ \\
\hline- & $5,4 / 7$ \\
\hline - & $2 / 2$ \\
\hline - & $4,9 / 2$ \\
\hline- & $1 / 1$ \\
\hline - & $12,5 / 2$ \\
\hline - & $8,7 / 4$ \\
\hline Genro & $2,5 / 6$ \\
\hline Filha & $2,9 / 3$ \\
\hline- & $2,5 / 1$ \\
\hline Esposa & $4,2 / 2$ \\
\hline Sobrinha & $5,8 / 3$ \\
\hline- & $8,3 / 6$ \\
\hline Filha & $5,6 / 7$ \\
\hline . & $2,2 / 2$ \\
\hline
\end{tabular}


açúcar do sangue baixa muito, outro dia mesmo dei um susto danado nela. (Sujeito 10)

São seis pessoas em casa lá. Todo mundo ajuda. A gente comia muito e muito fora de hora. A gente criou um horário para café que a gente não fica mais comendo tanta coisa e tão fora dehora. ( $N$ eta de10)

0 medicamento é eu que controlo. A dieta éa mulher, né? Eu tenho a nutricionista, ela me passa a dieta eeu passo para a mulher. E para cuidar dos pés eu peço para a minha mulher. Lixar, cortar, ela que olha e agora a operação cicatrizou graças à ajuda dela. (Sujeito16)

Eu tô há mais de vinte anos separado da muIher. M oro na mesma casa, mas em quarto separado, cama separada. M as ela me cuida. No que eu precisar ela ajuda. Ela que me dá a injeção. N esse ponto ela ajuda. (Sujeito18)

0 pessoal seapavorou porqueeles sabem queeu gosto muito de doce. M inha filha se preocupa, ela me cuida setô fazendo regi me, a dieta. (Sujeito 21)

Tabela 2. Distribuição da amostra por classificação de risco de lesão neuropática nos pés.

\begin{tabular}{cr}
\hline Categoria de risco & $\mathrm{n}(\%)$ \\
\hline 1 & $7(23)$ \\
2 & $11(37)$ \\
3 & $4(13)$ \\
4 & $8(27)$ \\
\hline
\end{tabular}

Eu não moro com eles, a gente vai lá para ajudar numa coisa ou outra, mas eu tenho alguém da família quesemprefica com eles. Q uando eu não to, tem a minha filha dequinze anos que ta lá ajudando, controlando. Eu ea fil ha dele, a gente fala bastantedo quetá se passando, dos cuidados. A gentelê alguma coisa, procura se informar. (Genro de 23)

Percebe-se que a rotina diária da doença é complexae, portanto, uma rede de solidariedade foi constituída no universo dos sujeitos estudados. Os sujeitos trocaram, com seus cuidadores, informações sobre os cuidados a serem adotados. Para que isso ocorra, é preciso existir o que M orin ${ }^{18}$ identifica como sendo "sentimento vivido de comunidade esolidariedade no interior de cada membro. É isso que dá uma realidade de existência a uma sociedade complexa".

0 diabetes mellitus interfere em importantes mecanismos de satisfação de desejos e necessidades. Dentre eles, destacam-se aqueles vinculados à ingestão de alimentos. Uma ruptura no fluxo cotidiano foi identificada em 46 ocorrências de menção feita a essa questão, por 24 pacientes e sete familiares do total de 41 entrevistados, que relataram uma reorganização de seus hábitos alimentares a partir do diagnóstico da doença. Isso confirma a afirmação de Snoek ${ }^{19}$ de que diabetes mellitus éa doen ça crônica de maior impacto psicossocial na vida do pacientee de seus familiares: 0 quemudou bastantefoi queassim na minha casa a gente come bastantedoce. Aí a mãecortou. E toda a família diminui em relação a ele. E a comida dele era feita separada. M as nisso ele até é bem fácil. Se ele só pode comer arroz, feijão e carne, ele come aquilo ali enão reclama. (Filha de 24)

Quadro 1. Temas identificados nas entrevistas e suas categorias, em ordem decrescente, com as frequências de ocorrência.

\begin{tabular}{|l|l|}
\hline \multicolumn{1}{|c|}{ Tema } & \multicolumn{1}{c|}{ Categorias (frequência de ocorrência) } \\
\hline Gestão da doença & $\begin{array}{l}\text { Disciplina diária e tratamento rigoroso (64) } \\
\text { Necessidade de mudança de hábitos alimentares (46) } \\
\text { Liberdade cerceada por terceiros (34) } \\
\text { Total: } 144\end{array}$ \\
\hline Cuidados com os pés & $\begin{array}{l}\text { Necessidade de ajuda (51) } \\
\text { Dificuldade física (19) } \\
\text { Situação de risco nos autocuidados (18) } \\
\text { Total: 88 }\end{array}$ \\
\hline \multirow{2}{*}{ Prevenção das complicações } & Desestimulada pela evolução silenciosa da doença (22) \\
neuropáticas & Estimulada pela experiência de uma complicação (22) \\
& Estimulada pelo conhecimento da experiência alheia de perdas (20) \\
& Total: 65 \\
& \\
\hline
\end{tabular}


Os achados do presente estudo corroboram os resultados do estudo de Pace et al..$^{20}$, no qual $50 \%$ dos 24 familiares entrevistados reconheceram que a família experimentou algum grau de mudança em relação à dieta como forma deapoio e incentivo ao paciente. Esta participação de terceiros no controle do diabetes parece ter uma influência positiva na adesão ao tratamento, como relatado por Wang eFenske ${ }^{21}$, quedemonstraram que os pacientes que tiveram apoio adequado de familiares e amigos aderiram melhor às recomendações de autocuidados.

Se por um lado o envolvimento da família é desejável e positivo, por outro lado, pode criar um espaço para conflitos. Considerando que a doença impõe restrições, sobretudo interdições alimentares, é preciso que os membros da família compreendam que esta tarefa podenão ser tão fácil para o paciente. 0 documento da Organização Mundial da Saúde sobre a educação terapêutica considera essa questão e enfatiza a necessidade de prover a família do paciente de apoio psicológico para lidar com as dificuldades do controle da doença ${ }^{1}$.

A percepção da participação da família como uma forma de controle que ameaçava a liberdade individual foi identificada em 34 ocorrências nas narrativas de onze $(36,6 \%)$ dos pacientes entrevistados, que não aceitaram se submeter às injunções como uma forma de resgatar o controle de suas próprias vidas: Ela (a esposa, que está junto, na sala) começa a falar na frente dos outros e eu falo: "tu melarga do meu pé, senão eu vou começar a beber de novo". Começa a me aporrinhar. Ela começa a me aporrinhar e o que eu tenho que fazer? (Sujeito 1)

A dieta édifícil porquetu tem que mudar tudo. E a gente tem hora que quer comer, se alguém tá vigiando, tu faz escondido (risos). (Sujeito 3)

$M$ aso (sujeito 4) não faz nada do queeledeve ria. Ele podia caminhar, fazer uns exerć́cios. Eu falo, falo, falo, mas ele tem que esnobar para se defender. (Esposa de 4)

Falei para ela tomar cuidado. Diabetes é uma doença que te prejudica cada dia mais. M as ela trabal hava em firma grandeeela ia pra festa enão cuidava mesmo, né? Aí, fal ei com ela bastante. Com diabetes não pode sair para tomar chope com os colegas. M as ela não ouve, não. Comecarnedeporco, não se cuida. (I rmã de 11)

0 sentido do self é muito interessante. Ao mesmo tempo em que sabem das prescrições, os pacientes transgridem. A entrevistada 20 verbaliza sua indignação com a cobrança externa de um controle rigoroso e reconhece que proibições se transformam em atrativos: $E$ aí, quanto mais a coisa é proibida, mais tu tem vontade de fazer. E me dava vontade de fazer o contrário. Às vezes, me dá vontade de comer. Autodomínio, tem que disciplinar e não comer. Mas eu, quando tu não pode comer, aí é que dá mais vontade etu come mesmo. A gora seninguém me controla, eu consigo mecontrolar. É muito interessante. (Sujeito 20)

Esta recusa dos pacientes em cooperar com seu próprio tratamento foi explicada por Fogarty ${ }^{22}$ em termos de uma "teoria de reatância", em que a ameaça à liberdade aumenta o desejo pelo risco. 0 autor enfatiza que a adesão ao tratamento é mais difícil quanto mais longo e complexo for o regime. Quanto mais o paciente sentir que sua liberdade está sendo cerceada, mais ele se sentirá motivado a resgatá-la. N este sentido, as pressões por parte da família podem ser percebidas pelo paciente como um problema maior que a própria doença, induzindo a respostas contrárias àquelas desejadas.

Os cuidados com os pés
realizados por terceiros

A análisedos relatos referentes especificamente aos cuidados de inspeção, higiene e limpeza dos pés revelou aspectos importantes acerca da vida dos entrevistados. A filosofia do autocuidado, em quese pretendea independência do doente e sua participação no tratamento da doença, precisa admitir a cooperação de terceiros como uma real idadedos pacientes diabéticos. Essa questão de dar ao outro a incumbência de cuidar dos pés não deixa de ser um aspecto muito importante da sociabilidade dos sujeitos. N este sentido, $86,7 \%$ dos pacientes entrevistados no presente estudo construíram suas próprias condutas junto com seus cuidadores, orientadas pelos preceitos dos cuidados médicos, levando o outro a aprender coisas que nem sempre faziam parte deseu repertório: Não ol ho todos os dias, só quando está medoendo. Peço ao J osépara cortar a unha, os cantinhos. Ele é que corta. Eu mesma nunca corto. É que eu tenho medo de cortar e cortar de mais e aí ficar a ferida. (Sujeito 2)

É a minha esposa. Ela queéminha enfermeira agora. Eu pedi a ela, senão eu teria que ir no posto todo dia. E ela faz de boa vontade, sem dúvida ne nhuma. Dois curativos por dia. E para cortar as unhastambém, é ela quefaz. Porque para levantar o pé para eu cortar a unha, é meio dificultoso, porque eu tenho problema de aparelho no fêmur esquerdo ea dificuldadezinha. Então, já tô acomodado e deixo para ela cortar, que ela faz com toda delicadeza. Dá tudo certo. (Sujeito 6) 
Grande parte dos pacientes entrevistados já estava com a visão comprometida em função do diabetes mellitus. 0 estágio da doença reduziu a possibilidade deen xergar em detalhes o queacontece com o próprio corpo. Assim, toda a filosofia do autocuidado foi cedendo espaço para uma outra forma de relacionamento com o outro. Nos relatos de catorze $(46,7 \%)$ dos pacientes entrevistados, a disfunção visual, a dificuldade física para chegar até os pés ou simplesmente a confiança de que o outro fosse mais habilidoso para as tarefas de higiene e limpeza aparecem como justificativa para uma dependência de terceiros: Sempre que eu desconfio de alguma coisa, eu dou uma olhadinha. E todo dia éela queolha (a esposa , acompanhante). Porqueeu não tenho como ol har entre os dedos. Às vezes, eu quero ol har em baixo para ver a sola dos pés e não consigo. (Sujeito 4)

Ah, as unhas. Tudo tá dependendo dos outros para fazer isso aí. Fazer uma faxina no meu pétem que ser outra pessoa, para cortar minhas unhas, tem que ser eles, né? M inha filha, essa que tava aí ontem, é que fez para mim, senão o meu velho mesmo que faz. Lixa aqui. Eu mesma não posso lixar queeu tenho medo de sair sangue. (Sujeito 8)

0 problema éo seguinte, queeu enxergo pouco, então tento dar uma olhada todos os dias. E para cortar as unhas, é a minha filha é que anda cortando. Ela enxerga bem, né? (Sujeito 9)

Quem corta as unhas para mim é a minha guria. Porque eu não consigo chegar até os pés. (Sujeito 12)

Eu não consigo olhar os pés, né?Q uem olha mesmo para mim éa minha esposa. Ela que me ajuda. Aténa hora do banho, quem meajuda éela. Quando ela tá em casa, ela me ajuda, né? Porque ela tem medo do queeu faço, porqueeu não enxergo mesmo. Tenho dificuldade para enxergar, então quem cuida dos meus pés é ela. Eu procuro orientar, na maioria das vezes, porque como eu sei o que eu preciso de cuidado, eu procuro orientar. (Sujeito 17)

Olha, doutora, não étodo dia, senão eu ia estar mentindo, mas tem um dia que as gurias (filhas) olham, cortam as unhas. E todo dia são elas que ol ham porque eu não tô enxergando nem o ferimento, as unhas. Enxergo muito pouco. As unhas eu pergunto, "como é que tão as unhas, como é que eu tô?" E calo eu não deixo tirar nada, doutora. Eu só faço a unha, as gurias quefazem bem cortadinho. E a cutícula elas não fazem, elas só cortam as unhas. Não mexem em nada e eu nem dexxo. (Sujeito 29)

Os cuidados de higiene e a detecção de lesões (ou sinais queas antecedem) em um péinsensível dependem da capacidade do indivíduo de se examinar. Considerando quea retinopatia surgecon- comitantemente com a neuropatia diabética, 0 cuidado com os pés, pelo paciente, podeestar comprometido. No caso de idosos, como são 53,3\% dos pacientes da amostra aqui estudada, esse comprometimento visual, associado às limitações articulares, dificulta a inspeção e execução desses cuidados. Essas questões são pouco exploradas no planejamento das intervenções educativas eisto podeser a causa da subutilização, pelos pacientes, dos conhecimentos adquiridos nos programas educativos. No estudo de Thomson e M asson ${ }^{23}$, apenas $14 \%$ da amostra total conseguiam examinar a superfície plantar dos pés.

Quando, sem condições ótimas, o paciente tenta real izar sozinho os cuidados de higiene dos pés, estabelece-se uma situação de risco de lesão. Isso foi abordado por catorze $(46,7 \%)$ dos pacientes entrevistados. Nas palavras do entrevistado 22, um senhor de 67 anos que tem grave comprometimento visual, constata-se que sua investida independente gerou uma lesão no quarto pododáctilo queculminou em amputação: Aquele acidente do pé (fala da amputação que teve), eu não contei em casa, mas foi com o cortador deunha. Eu cortei o calo e correu o sangue. Eu não contei em casa. (Sujeito 22)

Esta questão da dependência nos autocuidados é ainda pouco referida na literatura sobre a educação terapêutica de pacientes diabéticos, ape sar das recomendações da Associação Americana de Diabetes fazerem menção ao envolvimento necessário de um membro da família quando 0 próprio paciente não apresentar condições derealizar sozinho a inspeção e os cuidados dos pés ${ }^{17}$.

A prevenção das complicações

não existe desde o início da doença

A neuropatia é uma complicação crônica do diabetes mellitus. Sua evolução é "silenciosa", como nos relataram vinte $(66,7 \%)$ dos pacientes entrevistados, em 22 ocorrências. Isso nos remete a pensar que a falta de sintomas pode explicar a fraca adesão dos pacientes às recomendações que visam à prevenção. Segundo Fogarty22, é difícil obter adesão ao tratamento quando se trata de condições subclínicas, mesmo quando os pacientes têm ciência do risco potencial queisto representa à sua saúde. 0 autor explica que os limites impostos pelos programas profiláticos não sejustificam aos olhos do pacientediante deuma condição assintomática, não o mobilizando, assim, para atitudes preventivas. Segundo Brown et al. ${ }^{24}$, o fato das complicações surgirem tardiamente dificulta o reconhecimento da seriedade 
da doença por parte dos pacientes diabéticos e, consequentemente, a implementação de modificações no estilo de vida. M uitas vezes, são consequências irreversíveis, como amputações ecegueira, que alteram a consciência que o paciente tem de sua doença. Foram identificadas 22 ocorrências nas entrevistas de doze (40\%) dos pacientes entrevistados, ao relatarem que as perdas evidenciaram a necessidade de se envolver com 0 tratamento como forma de prevenir outras perdas: Eu não sabia a profundidade que tinha essa doença. Eu sei que tem uma série de coisas, como perder a perna, o dedo do pé, mas eu não levei muito a sério, no princípio. (Sujeito 4)

Eu achava que aquilo os outros tava brincando comigo. A gora que eu comecei a não poder caminhar quase, muita dor nas pernas. Aí eu me preocupei, já não tinha ânimo para fazer tudo. (Sujeito 12)

Q uando eu comecei a descobrir os danos, eu comecei a mecuidar maisum pouco. M as como eu sou muito relaxado, um dia mecuido, outro dia eu como. É uma doença muito difícil de ser dominada. Porque na diabetes, as pessoas têm uma certa fraqueza. Elas são dominadas pelo diabetes. (Sujeito 14)

Depois que me atacou as vistas, eu fiquei mais cuidadoso. Não sei seadianta agora, maseu tô fazendo o queé para fazer. Porquequando vem as complicação da doença, tu já está mais para lá que para cá. A gente custa a acordar que o problema é sério. A doença édanada, ela ésilenciosa. (Sujeito 17)

Agora eu cuido mais. De uns dois anos para cá que eu passei a cuidar mais. Depois que eu cortei esses dedos. Vê como são as coisas. D epois que a gente perde. Eu perdi esses dedos ali. (Sujeito 22)

Não éapenas a própria experiência, mastambém o conhecimento de histórias al heias de perdas provocadas pelo diabetes que pode funcionar como forma de reforço à necessidade de implementar cuidados preventivos. Foram identificadas vinteocorrências demenção a danos provocados por diabetes em terceiros, nas narrativas de onze (36,7\%) dos trinta pacientes entrevistados: Fiz o possível. Desde o início. Conhecia um senhor que tinha na rua que perdeu uma perna primeiro, depois perdeu a outra. Ele era colega do meu marido, dirigia caminhão, né? Ficou na cama, nem levanta mais. (Sujeito 7)

Eu fiquei com medo eagora tá cada vez pior, né? As pessoas, uns cortam. Lá perto da minha casa, tem uma senhora quejá amputou. Eu não sabia dos riscos. Não sei se essa doença já existe há muitos anos, não tinha tanta gravidade assim como parece que agora tem. Agora, eu vejo tem colega minha aleijada, que cortou a perna, bah. (Sujeito 15)
Olha, isso eu não faço, isso de cortar os calo. Eu prefiro usar uma pomada. Passar gilete. Eu já vi genteperder uma perna ou um péde cortar com a gilete. Eu já tenho precaução neste sentido. (Sujeito 30)

Garcia e Suárez ${ }^{25}$ utilizaram-se das palavras dos próprios sujeitos estudados para reforçar a idéia de que as experiências compartilhadas em grupos operativos têm mais impacto para o paciente do que pal estras eexplicações. No entanto, esta estratégia de apresentar complicações da doença, como, por exemplo, as amputações e úlceras em diabéticos, devem ser utilizadas com critério. Segundo Brown et al. ${ }^{24}$, o fatalismo é uma barreira para a motivação e adesão do paciente ao tratamento.

\section{Considerações finais}

No presente estudo, foram identificados problemas relacionados à execução dos autocuidados dos pés que repetem a realidade da gestão da doença em si: a demanda do auxílio de terceiros. Assim, a filosofia do autocuidado cedeespaço para uma rede de solidariedade quese forma em realidade no universo dos sujeitos. É nesta teia, em geral formada pelas pessoas mais próximas do pacienteem termos de parentesco, queo paciente interage com seu cuidador para o enfrentamento da doença, que inclui o cuidado com os pés. Portanto, éimportanteenvolver membros da família do pacientenos programas educativos para a prevenção das complicações nos pés, atendendo ao que é recomendação da O rganização M undial de Saúde desde 1998. Recomendação esta que não faz parte do perfil de programas apresentados na literatura ${ }^{7}$. Não se trata de fornecer informações ao familiar do paciente diabético, mas de discutilas e adequá-las às realidades enecessidades particulares e prepará-lo para lidar com um sujeito que vive o cotidiano de uma doença crônica.

As medidas de prevenção do pé diabético, lamentavelmente, são valorizadas pelos pacientes somente após uma experiência de complicação ou perda (úlcera, insensibilidade nos pés ou amputação) ou a partir do compartilhamento da experiência alheia. N esse sentido, os resultados desse estudo podem ser úteis para subsidiar o planejamento de atividades educativas em grupo com possibilidades de interação entre os participantes. A apre sentação das complicações da doença para o paciente e seu familiar não deve ter uma conotação de sentença de morte para que esta conduta não te nha efeito negativo na motivação eadesão do paciente às medidas profiláticas. 
Esta pesquisa limitou-sepor não abordar uma amostra semelhante em tempo de evolução da doença, porém sem risco de lesão nos pés. A inclusão desses sujeitos poderia avaliar se as complicações do pé diabético estão relacionadas a diferentes condutas no enfrentamento da doença, por parte dos pacientes e de seus familiares.

Sugerese, para futuros estudos qual itativos e quantitativos, a investigação das dúvidas e dificuldades mais frequentes dos familiares de pacientes diabéticos em relação aos cuidados com os pés.

\section{Colaboradores}

LL Cisneros trabalhou na concepção, execução e redação final do estudo; LAO Gonçalves trabaIhou na concepção do estudo e metodologia.

\section{Agradecimentos}

À Dra. Cristina Rolim N eumann, médica endocrinologista da Prefeitura de Porto Alegre (RS), pelo auxílio na viabilização da coleta dos dados. 


\section{Referências}

1. World Health Organization. Therapeutic Patient Education. Copenhagen: WHO; 1998.

2. Nair KM, Dolovich LR, Ciliska DK, Lee HN. The perception of continuity of care from the perspective of patients with Diabetes. Fam M ed 2005; 37:118124.

3. Pecoraro RE, Reiber GE, Burgess EM. Pathways to diabetic limb amputation: basis for prevention. Diabetes Care 1990; 13:513-552.

4. Grupo de Trabalho Internacional Sobre Pé Diabé tico. Consenso Internacional sobre Pé Diabético. Brasília: M inistério da Saúde; 2001. p. 67-68.

5. Mason J, O'Keeffe C, M clntosh A, Hutchinson A, Booth A, Young RJ. A systematic review of foot ulcer in patients with type 2 diabetes mellitus. I: prevention. Diabet M ed 1999; 16:801-812.

6. Papanas N, Maltezos E, Edmonds M. The diabetic foot: a plea for the elementary? Acta Diabetol 2006; 43:152-153.

7. Valk GD, Kriegsman DMW, Assendelft WJJ. Patient education for preventing diabetic foot ulceration. Cochrane Database Syst Rev 2005; 25(1):CD 001488.

8. Lutfey KE, Wishner WL. Beyond "compliance" is "adherence". Diabetes Care 1999; 22:635-639.

9. Denzin NK, Lincoln YS, editors. Handbook of qualitative research. Thousand Oaks: Sage Publications; 1994.

10. Turato ER. Introdução à metodologia da pesquisa clínico-qualitativa - Definição e principais características. Rev Port Psicossom 2000; 2:93-108.

11. Sims DS, Cavanagh PR, Ulbrecht JS. Risk Factors in the diabetic foot. J Am Phys Ther Ass 1988; 68:18871902.

12. Turato ER. Tratado da metodologia da pesquisa clínico-qualitativa. Petrópolis: Vozes; 2003.

13. Jovchelovitch S, Bauer MW. Entrevista narrativa. In: Bauer M W, Gaskell G, organizadores. Pesquisa qualitativa com texto, imagem e som - um manual prático. 3a ed. Petrópolis: Vozes; 2002. p. 90-113.

14. Gill R. Análise do discurso. In: Bauer M W, Gaskell $G$, organizadores. Pesquisa qualitativa com texto, imagem e som - um manual prático. 3a ed. Petrópolis: Vozes; 2002. p. 244-270.

15. M inayo M CS. 0 desafio do conhecimento: pesquisa qualitativa em saúde. São Paulo: Hucitec; Rio de Janeiro: Abrasco; 1992. p. 89-104.
16. Bardin L. Análise de conteúdo. 3ạ ed. Lisboa: Edições 70; 2004. p. 89-125.

17. American Diabetes Association. Standards of medical care in Diabetes. Diabetes Care 2005; 28(Suppl):4-36.

18. Morin E, Le Moigne JL. A inteligência da complexidade. 3a ed. São Paulo: Petrópolis; 2004.

19. Snoek FJ. Breaking the barriers to optimal glycaemic control - what physicians need to know from patients' perspectives. Int J Clin Pract Suppl 2002; 129: 80-84.

20. Pace $A E$, Nunes PD, Ochoa-Vigo K. O conhecimento dos familiares acerca da problemática do portador de diabetes mellitus. Rev. Latino-Am Enfermagem 2003; 11:312-319.

21. Wang CY, Fenske M M . Self-care of adults with noninsulin-dependent diabetes mellitus: influence of family and friends. Diabetes Educ 1996; 22:465-470.

22. Fogarty JS. Reactance theory and patient noncompliance. Soc Sci M ed 1997; 45:1277-1288.

23. Thomson FJ, Masson EA. Can elderly diabetic patients co-operate with routine foot care? Age and Ageing 1992; 21:333-337.

24. Brown JB, Harris SB, Webster-Bogaert S, Wetmore S, Faulds $C$, Stewart M. The role of patient, physician and systemic factors in the management of type 2 diabetes mellitus. Fam Pract 2002; 19:344-349.

25. Garcia RG, Suárez RP. Diabetes education in the elderly: a 5 year follow up of an interactive approach. Patient Educ Couns 1996; 29:87-97.

Artigo apresentado em 18/01/2008

Aprovado em 29/10/2008

Versão final apresentada em 08/11/2009 